\title{
Frequencies for Radio Astronomy
}

by

F. G. SMITH

Nuffield Radio Astronomy Laboratories, Jodrell Bank, Cheshire
At present the scope of research in radio astronomy is limited by the allocation of frequencies, some of which have to be shared with other radio services. When the International Telecommunications Union reconsiders all frequency allocations next year, astronomers are hoping for an improvement.
THE allocation of bands of frequencies to the many radio services is a matter for agreement between nations. A series of conferences, arranged by the International Telecommunications Union (ITU), have dealt with various parts of the spectrum and with various services, so that there is now an agreed allocation for all frequency bands from $10 \mathrm{kHz}$ to $40 \mathrm{GHz}$. In this agreement, the needs of scientific research must be presented, along with those of all radio services, by national administrations and not directly by the scientists. Coordination of the individual national proposals must therefore be achieved through tho combined action of three international scientific unions, IAU (astronomy), COSPAR (space) and URSI (radio), which jointly delegate members to an Inter-Union Commission for the Allocation of Frequencies for Radio Astronomy and Space Science (IUCAF). This Commission discusses the scientific case for protecting various frequency bands for space research and radio astronomy, and informs scientists and administrations throughout the world of the desirable and practical steps that can be taken to improve and extend the allocations.

There will be a new World Administrative Conference of the ITU in June 1971, covering frequency allocations for all space activities, notably for satellite communications. IUCAF has made several suggestions for revising the allocations, especially for radio astronomy; these have been passed on to national administrations, and there is reason to hope that most of the IUCAF suggestions will become firm proposals with a good chance of acceptance at the conference.

Space research seems to be fairly well catered for in the existing regulations, apart from a difficulty in obtaining the use of some low frequency bands for ionospheric research. IUCAF is seeking an improvement in the protection of the "guard bands" around standard frequency transmissions for this purpose.

The more complex problem of radio astronomy is set out in the table, which lists existing allocations together with the latest IUCAF proposals. Two kinds of allocation are required: a series of bands to cover the whole spectrum at roughly octave intervals, for continuum radiation, and some individual bands to cover the most important radio spectral lines.

Some bands already allocated are shared with other services, such as "fixed and mobile", that is communications such as taxi radio. This is only possible when radio observatories and the other users are geographically widely separated; even so, sharing is often a serious limitation on the sensitivity of the radio astronomical work. There are also differences between the three "regions" of the world, defined by ITU. In any table the word "sharcd" covers a range of meanings. The ITU regulations include "secondary allocations", "shared allocations" and various forms of footnotes; all these are here designated as "shared".

The table represents the present state of discussions. There will be many more discussions during the coming
Table 1. EXISTING ALLOCATIONS OF FREQUENCIES TO RADIO ASTRONOMY AND

\begin{tabular}{|c|c|}
\hline Frequency band & Present status \\
\hline $\begin{array}{l}\text { Approx. 10 } 10 \mathrm{MHz} \\
\text { (bandwidth } 20 \mathrm{kHz} \text { ) }\end{array}$ & None \\
\hline Approx. $20 \quad \begin{array}{cc}\mathrm{MHz} \\
\text { (bandwidth } \\
20 \mathrm{kHz} \text { ) }\end{array}$ & None \\
\hline $37 \cdot 75-38 \cdot 25 \mathrm{MHz}$ & Shared \\
\hline $73-74 \cdot 6 \mathrm{MHz}$ & $\begin{array}{l}\text { Region } 2 \text { only (N. } \\
\quad \text { and } S . \text { A merica) }\end{array}$ \\
\hline $150 \cdot 5-153 \mathrm{MHz}$ & $\begin{array}{l}\text { Region } 1 \text { only } \\
\text { (Europe). Shared }\end{array}$ \\
\hline $404-410 \mathrm{MHz}$ & Shared \\
\hline
\end{tabular}

404-410 $\mathrm{MHz}$

Shared

$606-614 \mathrm{MHz}$

Allocated to televi- IUCAF asks for this band to be sion, but so far allocated to radio astronomy unused 1,400-1,427 $\mathrm{MHz}$
(the hydrogen line) $\begin{gathered}\text { Exciusive allocation An extension to lower frequen- } \\ \text { to radio astronomy }\end{gathered}$ cies-down to $1,390 \mathrm{MHz}-$ is needed for observation of galaxies with large redshifts

1,664.4-1,668.4 MHz Shared

(the oH line)

Protection is sought from airborme transmitters in this band, and an extension to sible

1,612 and $1,720 \mathrm{MHz}$ None

(other $\mathrm{OH}$ lines)

Some local protection is sought for individual observatories observing these lines

2,690-2,700 $\mathrm{MHz}$ Exciusive allocation An extension down to 2,670 to radio astronomy $\mathrm{MHz}$, on a shared basis, is requested for wide-band observations of extragalactic
sources

$4,990-5,000 \mathrm{MHz}$

Exclusive in Region $2(N$. and S. Ameriand an extension down to 2a), shared else- $\quad 4,950 \mathrm{MHz}$, both seem pos-
cal sible and are requested by
IUCAF

$10 \cdot 68-10 \cdot 70 \mathrm{GHz}$

Exclusive allocation to radio astronomy (with some exceptions)

$15 \cdot 35-15 \cdot 40 \mathrm{GHz}$

Exclusive allocation to radio astronomy (with some ex-

ceptions)
Exclusive to radio This band is needed for satellite

$10 \cdot 3-19 \cdot 4 \mathrm{GHz}$ astronomy, with communications, and will be some exceptions relinquished by radio astronomers

$23 \cdot 0-23 \cdot 5 \mathrm{GHz}$

Proposed for exclu- Replacement for the 19.3-19.4 sive allocation to
radio astronomy

Exclusive to radio No change is proposed astronomy with some exceptions

A series of bands, for It is proposed to preserve wide example, $88-92 \quad$ bands in this region initially
$\mathrm{GHz}$

$40-240 \mathrm{GHz}$

There are also requests for some protection to be given to observations of the three following spectral lines: formaldehyde, $4,825-4,835 \mathrm{MHz}$; formaldehyde, 14.485-14.515 GHz; water vapour, $22 \cdot 21-22 \cdot 26 \mathrm{GHz}$.

year, and many weeks of work at the conference itself. IUCAF has asked to have an observer at the conference, so that the scientific case for the various proposals is available at all times. Fortunately many of the people concerned with formulating the next international agreement realize that the electromagnetic spectrum is a natural resource that can be despoiled as effectively as any other, and it is to be hoped that considerable improvement will be obtained in the status of frequency allocations for scientific research. 